\title{
Participation patterns of elementary students in scientific problem finding activities
}

\author{
Kicheol Oh ${ }^{1}$ and Nam-Hwa Kang ${ }^{2^{*}}$ (1)
}

\author{
* Correspondence: nama.kang@ \\ knue.ac.kr \\ ${ }^{2}$ Department of Physics Education, \\ Korea National University of \\ Education, Cheongju, Republic of \\ Korea \\ Full list of author information is \\ available at the end of the article
}

\begin{abstract}
Opportunities for students to develop problems for scientific investigation have rarely been provided in South Korean science classrooms. The purpose of this study was to examine the nature of elementary students' participation in problem finding in science learning. Specifically, we examined the characteristics of student participation in problem-finding activities in search for productive ways of student engagement in problem-finding and their conditions. Data from six groups of students from two elementary schools were analyzed. Data sources included recordings and transcripts of students' group conversations during problem-finding activities and follow-up interviews, student worksheets completed as a group, and field notes. The findings showed that typical elementary students were able to generate problems for scientific investigation. They kept mostly on task, and enjoyed the activity. We identified three different problem-finding discourse patterns and conditions for productive questioning, which provided ways to facilitate students' problem finding in science learning. Further research questions are discussed.
\end{abstract}

Keywords: Problem finding, Inquiry problem construction, Elementary students, Participation

\section{초록}

한국의 과학수업에서 학생들이 탐구문제를 스스로 찾는 기회가 많이 주어지지 않는다는 연구를 바탕으로 이 연구에서는 초등학생들이 과학수업 시간에 탐구 문제를 스스로 찾는 문제발견 활동에 참여하는 방식과 성격에 대해 조사하였 다. 특히, 학생들이 생산적인 방식으로 문제발견에 참여하는 특성과 조건에 대 해 조사하였다. 학생들의 문제발견 활동 중 모둠 담화와 활동 후 학생 면담을 녹음하여 전사 후 분석하고, 연구자가 비참여 관찰 중 기록한 학생활동 관찰지 와 학생들이 완성한 학생활동지도 분석하였다. 연구결과 일반 초등학교 6 학년 학생들이 탐구 문제를 적절히 만들어 낼 수 있음이 드러났다. 본 연구에서 학 생들은 문제발견 활동에 대체로 집중하였고 적극적으로 참여하였다. 또한 세 가지의 문제발견활동 관련 모둠 담화 유형이 드러났고, 이로부터 학생들의 문 제발견활동을 촉진하는 전략을 추출하였다. 연구결과를 바탕으로 후속 연구 주제를 제안하였다.

핵심어: 문제발견탐구문제구성초등학생참여 
New scientific discoveries or developments amaze lay people and arouse curiosity about scientists' creativity and the process by which such novel scientific achievements are reached. Finding meaningful results in science requires a deep knowledge of the field and the skills to be able to recognize and identify problems in specific situations. Indeed, scientists noted that problem finding was an important factor in their scientific achievements, and that the choice of a particular research question determined the production of creative results (Mansfield \& Busse, 1981). For example, Einstein stated, "The formulation of a problem is often essential than its solution .... To raise new questions, new possibilities, to regard old questions from a new angle, requires creative imagination and marks real advance in science." cited by (Getzels, 1979), p.168. The vast majority of new scientific achievements and developments stem from a human ability to grasp extremely ordinary things as completely different new problems.

If scientists have led the development of outstanding science through the discovery of problems and the novelty of research topics, the experience of finding creative problems through science education will be important for students in science learning. Bruner (1996) also emphasized the importance of questioning in science education:

Good science teachers ... do just what I have been proposing: place the emphasis on live science making rather than upon the achieved remains of, so to speak, already accomplished science .... "The art of raising challenging questions is easily as important as the art of giving clear answers." And I would have to add, "The art of cultivating such questions, of keeping good questions alive, is as important as either of those." (p.127).

Recent curriculum reform also emphasizes problem finding as an importance part of science learning. Scientific practices addressed in the science education curriculum in South Korea or science education standards in the US include "proposing problems" or "defining problems" (Korea Ministry of Education, 2015; National Research Council, 2012a; NGSS Lead States, 2013).

In an increasingly sophisticated knowledge and information society, creativity is at the heart of education. Creativity as a thinking capacity is considered to be one of core twenty-first century competencies (National Research Council, 2012b) and is also included as such in the science education curriculum in South Korea (Korea Ministry of Education, 2015). Developing problem solving skills in students has long been a critical goal of science education, but with greater emphasis on creativity in education, creative problem solving has emerged as an important curricular goal in Korean science education (Korea Ministry of Education, 2015) as well as other countries (National Research Council, 2012b; Treffinger, Isaksen, \& Dorval, 2000).

Discovering problems in the process of creative problem solving has been researched in the area of creativity education, as well as science education (Duschl, Schweingruber, \& Shouse, 2007; Hoover \& Feldhusen, 1994; Kozbelt, Beghetto, \& Runco, 2010; Runco \& Chand, 1994; Ryu \& Park, 2006). In cognitive science, a problem is defined as a state where a situation is not in the state wanted by the problem solver, and there is no obvious way of transforming a given state to the goal state. Problems are typically categorized as well-defined, or ill-defined. A well-defined problem occurs when the given state, goal state, and allowable operators are clearly specified. An ill-defined problem occurs when the given state, goal state, and/or allowable operators are not clearly specified. Problem solving is defined as, "cognitive processing directed at transforming a given situation into a goal situation when no obvious method of solution is available to 
the problem solver" (Mayer, 2006), p.146, and creative problem solving is related to ill-defined problems. On the other hand, in science education research, problem solving has been considered as the main activity that scientists engage in for developing theories or models (Duschl et al., 2007). Thus, problem solving refers to cognitive process as well as the activity itself. Problem finding is a part of problem solving, and involves problem solvers' identification of problems to be solved. In the literature on problem solving, it is called many different terms, including 'problem identification', 'problem construction', and 'problem definition' (Kozbelt et al., 2010). Problem finding is an appropriate term for this study, because it highlights students' creativity and cognitive engagement in the exploratory stage of searching for questions in the beginning of science inquiry (Ryu \& Park, 2006).

Getzels and Csikszentmihalyi first used the term of problem finding in their study of artists in drawing paintings (Weisberg, 2006), p.140. Getzels (1979) theorizes that problems never exist a priori, but rather than humans create or pose problems, and solve them. According to him, the quality of problems decides the quality of solutions. Fruitful, innovative or radical problems can lead to new methods of generating solutions. Thus, problem finding is itself as an intellectual process as generating solutions. In formulating creative problem solving processes, Treffinger (1995) defined problem finding as part of understanding the problems in a given task or situation. According to him, a problem solver will initially identify an area to focus on in a given situation, and then identify the necessary information. After this basic work, the problem solver will identify a specific or targeted question to focus on, i.e., specific problems for investigation, or solutions to be formulated. Similarly, Runco and Chand (1994) describes that problem finding comprises a range of behaviors including problem identification and problem definition. The differentiation between the two lies in specificity and problem definition happens when "tasks are manageable" (Runco \& Chand, 1994), p. 44. Problem finding also involves intuition or "feeling" such as "sensing gaps, "dissatisfaction with the status quo," or "frustration or irritation that something doesn't work as it might" (Wakefield, 1994), p. 99. These feelings can be connected to scientific curiosity and motivation to know in which students feel gaps in their knowledge and want to fill the gap.

With regard to scientific creativity demonstrated in problem finding, Kim, Seo, and Park (2013) identified situations of scientists' problem-finding. They identified 10 exemplary creative scientists such as Galilei, Kepler, Carnot, and Mendel and analyzed their problem-finding situations. The results showed that the scientists recognized problems when they found existing explanations to be incomplete or contradictory or when they identified new phenomena that could not be explained by existing knowledge. These findings about scientific problem-finding situations seem to be related to intuitions involved in problem finding suggested by Wakefield (1994).

In order to utilize creative problem finding as a scientific and multi-dimensional creative act in science learning, there must be a problem situation that can lead to exploration or curiosity. Ill-defined problem situations are typical conditions for finding problems that can lead to students' creative skills and attitudes (Ryu \& Park, 2006). Thus, ill-defined problems or problem situations have been used for creative problem finding activities. For example, for science high school students' problem finding activities, Ryu and Park (2006) used two levels of complexity for problem finding situations for high school students. One is a less complex situation where lab materials are provided in words (distilled water, ethanol solution, and ether) asking students to come up 
with possible problems for investigation with those materials. As a more complex problem situation, they used pictures of a scuba diver under water and a hiker at the top of Mountain Everest to ask students to come up with problems for investigation. With those problem situations, they found that students followed stages of problem finding including exploring the problem situation, discussing relevant knowledge and experience, examining potential problems, evaluating the appropriateness of problems, and selecting problems. They also found that students came up with more problems about the less complex problem situations by applying knowledge from more diverse areas.

Research demonstrates that problem finding is an effective strategy for developing students' creativity, an important aspect of scientific practices, and thus an important goal for science education. However, in South Korean science education, there has been a lack of emphasis on providing students with opportunities to find their own problems for investigation. For example, Kang and Lee (2013) found that there was only one occasion in which students were required to pose their own problems for investigation in all high school physics textbooks. Given that science education in South Korea primarily textbook-based, the finding demonstrates the very small opportunity that students have in finding scientific problems for their own investigations.

On the other hand, there has been research on students' problem-finding abilities with secondary students and elementary students, which demonstrates that students are able to find meaningful problems (Kim \& Lee, 2013; Ryu \& Park, 2006). Most of these studies examined results of student problem-finding activities, rather than processes that can provide insight into how to teach. Also, most of these studies examined special students (e.g., gifted students) or student in special settings and seemingly assumed that problem finding requires proper knowledge base or higher level thinking skills on the part of students. However, it is hard to find strong evidence that requires students' cognitive abilities or background knowledge as a condition for problem discovery. With the rich amount of information easily provided by the Internet, it is expected that conditions such as background knowledge will become less important. Therefore, it is necessary to qualitatively examine the possibility and process of problem finding of typical elementary school students.

The purpose of this study was to examine the nature of elementary students' participation in problem finding in science learning. In particular, we were interested in patterns of students' conversations during problem-finding activities in order to gain insight into ways for facilitating problem finding in science learning. Two research questions guided this study: (a) What are the characteristics of student participation in problem-finding activities? (b) What are the productive ways in which students engage in problem-finding activities? To answer these questions, we have examined small group interactions by analyzing student utterances during the activity.

In South Korean science education literature problems for scientific investigation has been called, inquiry problems, and the current national science curriculum includes identifying science inquiry problems as one of key skills for students to use and develop through science learning (Korea Ministry of Education, 2015). On the other hand, the national science education standards frame in the US distinguished problems from questions in science education by using questions for scientific inquiry and problems for engineering design (NGSS Lead States, 2013). In a dictionary (Merriam-Webster's Online Dictionary, 2019), a problem is defined as, "a. question raised for inquiry, consideration, or solution; b: a proposition in mathematics or physics stating something to 
be done" and a question is defined as, "(1): an interrogative expression often used to test knowledge; (2): an interrogative sentence or clause." These definitions overlap, and the literature on problem finding uses the two terms interchangeably. Thus, in this paper we used the two terms interchangeably following the literature on problem finding that generally do not distinguish the two.

\section{Methods}

\section{Student activity sheet development and implementation}

We constructed student activity sheets to help elementary school students' problemfinding activities in consultation with five researchers who had elementary school teaching experience. We adapted the two levels of problem situations used by Ryu and Park (2006). We created two problem situations with different levels of complexity. Given that the activity was for elementary students, we used pictures for both levels. As a relatively simple problem situation, we provided students with three pictures: pictures of a cup of water, a pile of soil, and various seeds. As a complex problem situation, we provided students with eight pictures: pictures of plants in greenhouse, racing car on race, smoking chimneys of factories, street lights on a road, lightening in the sky, a vessel in the ocean, a white bear on an iceberg, and a lava mountain. These pictures were from science textbooks representing different areas of science (e.g., biology, physical science, and earth science). Research that explored how individuals generate ideas showed two-step general thinking processes: generating ideas and exploring their implications (Smith, 1995). Accordingly we designed problem finding activities by asking students to (a) come up with questions about the phenomena shown in the pictures, and (b) reflect on their appropriateness as scientific inquiry problems. The second step in particular asked students for metacognitive thinking expected in facilitating creative problem solving (Kozbelt et al., 2010); p. 32.

To explore the possibility of elementary school children's problem-finding, we pilot tested the initial activity sheets with 5th- and 6th-grade students. The pilot results showed that the students were able to find inquiry problems in some photos, but not all. Also found was that the activities were limited in guiding students' evaluation of their problems to determine appropriateness for scientific inquiry. Thus, we organized the problem-finding activity into three stages: exploration of scientific inquiry questions, problem finding about simple situation (activity I), and problem finding about complex situation (activity II).

The three stages were implemented over three, 40-min class periods. All these were implemented in regularly scheduled science classes. During the scientific inquiry problem exploration phase, students were introduced to the definition of inquiry question, its quality criteria (Table 1), and the importance of problem discovery in science using historical cases. The inquiry problem quality criteria was based on the notion that scientific knowledge is developed based on empirical evidence, as noted in the Korean science curriculum and wider literature (Korea Ministry of Education, 2015; Kuhn, Black, Keselman, \& Kaplan, 2000), and scientific investigation appropriate for young children should be sensitive to the capability of the learners. Among the quality criteria, students were told that questions that can be directly answered by a search on the Web (consideration item on Table 1) were not preferable as inquiry questions because the problem for inquiry should be answered through scientific investigation. In the second and third periods, assigned to activity 1 and activity 2 respectively. In each activity, the students were asked to identify 
Table 1 Inquiry problem criteria

\begin{tabular}{ll}
\hline Criteria & Specification \\
\hline Feasibility & Is it a problem you can explore yourself? \\
Scope & Can the problem be narrowed down and specified to be answerable? \\
Objectivity & Can the question be answered through observation or measurement? \\
Consideration & Is it a question that can be directly answered by information found on the Web? \\
\hline
\end{tabular}

problems/questions in relation to the given photos and determine the appropriateness of inquiry problems. From the pilot test, we also found that students were distracted by individual worksheets during group discussions. Thus, we used one, large worksheet per group for the activities. Thus, the students were required to submit their inquiry questions as a group at the end of the period.

\section{Participants}

Since this study is a case study for exploration, we used a convenient sampling method. A total of 32 students from two elementary schools participated in this study. A class of 19 students were from $\mathrm{K}$ elementary school, a typical small city school whose parents were highly interested in their children's education. The other 13 students were from a class at Y elementary school, a typical rural school that keeps losing students due to rural flight. ${ }^{1}$

Each of the students' classroom teachers implemented the study in their three regularly scheduled science class periods. Prior to implementation, the researchers provided sufficient explanations to the teachers about the purpose of the study, and the intention of the worksheet. Most of the class periods were guided by the worksheets, while the teachers interrupted students' group work to pace them so that students could finish the activities in time. One of the authors of this paper was a non-participant observer, taking field notes throughout three class periods in both schools.

\section{Data collection and analysis}

Video and audio recordings of student group interactions, group worksheets, and field notes were collected during the three class periods in both schools. Also, we interviewed a number of the students a week after the class activities to triangulate initial data analysis. Some of the recording files were lost during data processes and thus, the final data analyzed for this paper were from three groups of 13 students from Y school (Groups A, B, \& C), and three groups of 14 students from K school (Groups E, F, \& G). For analysis, we transcribed all the audio recordings of group interactions and interviews.

We used student utterance as a unit of analysis. Utterance is a unit of spoken language separated, "by conversational turn-taking or via clear pauses within the flow of speech" (Psychology Dictionary, 2019) and most classroom verbal interaction analysis research uses it as a unit, or as a component of a unit of analysis (Lee et al., 2013; Lee, Choi, Lee, Shin, \& Song, 2013; Lemke, 1990). For each unit, we used the following coding scheme: total number of utterance, levels of utterance, utterance bundles, problem types and creativity of problems. Typically, the quantity of utterances by students (total

${ }_{1}^{1}$ In South Korea, urban schools tend to be more competitive due to higher population and parents are more interested in children's education. 
number of utterance) indicates the degree of student engagement in the activity. Levels of utterances were used to identify the degree of cognitive engagement of students.

We coded students' utterances into five levels: level 1 was off-topic utterance, level 2 was a comment on activity itself, level 3 was posing a problem or question, level 4 was extension of proposed problems or questions, and level 5 was evaluation of problems or questions on the table. Utterance bundles were defined as a sequences of students' utterances over one topic. Utterance bundles in relation to who was included in the bundle could indicate inclusiveness of group talk. Using the definition, we grouped students' utterances into bundles in the transcripts. Problem types were divided into two categories: simple problems, and inquiry problems. In the study about scientifically-gifted high school students' problem finding, Ryu and Park (2008) categorized problems constructed by students into seven types, such as problems of measurement, problems of investigation method, problems about causes, problems about comparison, and so on. Because we were more interested in participation patterns, rather than the type of problems students came up with, we decided to simplify the category to reflect students' scientific engagement. Questions passing the quality criteria listed on Table 1 were coded as inquiry questions, and the others were coded as simple questions. In doing so, we were able to explore whether elementary students are able to construct problems for scientific investigation. We then examined the creativity of problems in terms of flexibility, originality, and elaboration (Kaufman, Plucker, \& Baer, 2008; Ryu \& Park, 2006). Some problems were also coded as creative, but creative problems do not necessarily coincide with inquiry problems as they were identified with different criteria.

Based on the literature described in the introduction of this paper, two researchers developed the data coding scheme together, and coded the data using the scheme independently. Most coding results by the two researchers were consistent, excepting a few cases of coding student problems categories. Inconsistency in coding occurred mostly in deciding the feasibility and scope of students' problems as inquiry or not. In consultation with elementary science curriculum and science education researchers with elementary teaching experiences, the inconsistent coding results were resolved. For example, a problem, "How can dirt decompose things?" were coded differently by the two researchers. However, based on the elementary science curriculum, the question was determined as a known answer problem. Thus, it was determined to be a simple problem rather than an inquiry problem.

\section{Results}

\section{Characteristics of participation}

\section{Proportion of task-related utterance}

For each group's discussions, we calculated the proportion of task-related utterance to the total number of utterance (Table 2). On average, 305 total utterances per activity were made in each group, among which $68 \%$ were made within an utterance bundle and $60 \%$ of utterances were task-related. Most of the off-task utterances were social or task management. Thus, students mostly focused on problemfinding tasks.

The proportion of utterance bundles, i.e., students' continuous conversation over a given topic, could also indicate the degree of students' focus on the task. An utterance bundle had a mix of task-related (utterance level 2 or above), and task management or 
Table 2 Small group aidalogue patterns

\begin{tabular}{|c|c|c|c|c|c|c|c|c|c|c|c|c|c|}
\hline \multirow{2}{*}{$\begin{array}{l}\text { Group ID } \\
\text { Activity }\end{array}$} & \multicolumn{2}{|l|}{ A } & \multicolumn{2}{|l|}{ B } & \multicolumn{2}{|l|}{ C } & \multicolumn{2}{|l|}{$E$} & \multicolumn{2}{|l|}{$\mathrm{F}$} & \multicolumn{2}{|l|}{ G } & \multirow[t]{2}{*}{ Average } \\
\hline & I & $\|$ & I & $\|$ & I & $\|$ & I & $\|$ & I & $\|$ & I & $\|$ & \\
\hline Total no. of utterance & 220 & 244 & 328 & 220 & 291 & 241 & 366 & 421 & 387 & 358 & 237 & 342 & 305 \\
\hline Utterance bundle (\%) & 70 & 73 & 51 & 75 & 59 & 69 & 68 & 62 & 48 & 83 & 72 & 90 & 68 \\
\hline On-task utterance (\%) & 59 & 50 & 54 & 60 & 63 & 56 & 60 & 63 & 58 & 66 & 68 & 66 & 60 \\
\hline
\end{tabular}

off-task (utterance level 1) utterances. The following excerpt shows a typical conversational move in an utterance bundle.

II-C4: If we freeze our milk, will it sink? Let's make it (our inquiry question). [L3].

II-C2: You don't just use it. You can write it on paper. [L1].

II-C3: No! I'll write it down there. [L1].

II-C2: No, I don't like that. [L1].

II-C4: Hey, everybody! Let's do this one. Will frozen milk sink? [L2].

II-C2: Okay. Will frozen milk sink in water? [L2].

II-C3: Let's write that down (as our inquiry question). [L2].

II-C2: We can pour the milk into ice cube trays and put them in the freezer ... [L2].

(Group C in activity II; Utterance level coding in brackets)

In the excerpt, five out of eight utterances were task-related, and the others were task management. This task-related utterance proportion is near average.

\section{Conversation patterns}

In the recordings of small group discussion, three types of conversation in problem finding were identified. The first type (type I) is the one in which students continue to pose problems and opinions without responses. The second type (Type II) is the one in which the initial problem offered is continually modified or reshaped as different problems. The third type (type II) is the one in which the initial problem proposed continues to be elaborated to become a problem to be included in group reports.

An example of type I by the group B in the activity II is the following. Student B4 first proposed a problem but never received feedback on it. Instead, the other members presented their own problems and without feedback on her first one, student B4 proposed another one.

II-B4: How many polar bears are there now?

II-B2: How harmful are gas lamps?

II-B1: Can the question be about a motor (in the picture)?

II-B4: Why do volcanoes burst?

II-B3: How does a ship move?

Instead of responding to each other's problem, students in this type of conversation kept suggesting their ideas. Receiving no feedback from the members seemed to be perceived as an indication that the problem proposed was poor quality, encouraging them to continue proposing new questions. 
In type II, as shown in the case of group C in the activity I, an initial problem offered by a member was not explicitly addressed. Instead, the other students spun off the proposed problem into another one. In the example, C2's initial question about planting seeds led to a series of questions about planting seeds, rather than getting feedback on the initial question. In this pattern of conversation, a problem about a topic led to similar ones about the same topic, and thus the initial question played a role of calling attention to a certain topic.

I-C2: What happens if you change the order of planting seeds (between pouring water and putting seed)?

I-C1: What happens if you put soil and seeds at once when planting seeds?

I-C2: What happens if you use water with coloring when planting seeds?

Although quite a number of problems were offered in both types of conversation, there was no discussion on the meaning or the adequacy of the question. Even though these various and abundant problems were recorded in the audio, the students did not pursue them in their latter discussion. Thus, most of these various problems were lost, regardless of their quality.

In contrast to the two types of conversation aforementioned, in type III conversation, an initial question received responses by group members and was elaborated thereafter. For example, in group A's conversation in the activity I, students commented on an initial question, "Will seed grow without soil?" as the following. Student A3 asked for further elaboration of A2's initial problem and in doing so, the initial problem became clearer for scientific investigation.

I-A2: Will seeds grow without soil?

I-A3: What else will there be? Is it possible for seeds to sprout without soil?

I-A2: Just ... If you just throw seeds and water in places like this (pointing at the desk), will the seeds sprout?

I-A3: Can seeds sprout only with water?

I-A2: Can seeds sprout only with water and without soil?

Similarly, in the following example of group G's conversation in the activity I, students kept commenting on the initial problem and clarified it as a group.

I-G4: Ah! How deeply the soybean is planted will affect its growth?

I-G1: You mean depth?

I-G4: Yes. You can plant beans like this much (showing a depth) or this much (showing a different depth), for example. Can it be experimented?

I-G1: Yes!

I-G3: Of course!

I-G4: Then you write that down.

I-G3: What did you say? (Confirmation question for recording).

I-G1: So, depending on how deeply you plant the beans...

In the type III conversation, as shown in the group G's excerpt, problem evaluation played a critical role. As the students were asked to finalize inquiry problems based on 
the criteria, students used criteria of inquiry problem to determine their group's inquiry problems among those proposed by their members. This sometimes helped students elaborate their questions.

Students were sometimes distracted by details when elaborating or justifying their inquiry problems. For example, as shown in an example of group C's conversation during the activity I, students focused more on experimental processes, and less on elaborating problems when evaluating an inquiry problem based on the criterion of testability.

I-C1: Let's do this problem. What happens if you add colorings or drinks to water when planting seeds?

I-C3: Where can we get pigments for coloring water?

I-C2: You can get them in a grocery store 'XX Mart'. You can get brown color.

I-C4: Oh, yeah. But you can't get green or red color?

\section{Productive participation}

\section{Conditions for productive questioning}

We examined whether the two different types of activity made a difference in students' problem finding. We examined the total number of problems created by the students, and the total number of inquiry problems per each activity. For each activity, students generated an average of 36 problems (Table 3). Of these, about $20 \%$ of the problems were inquiry problems. When comparing the two activities, two groups presented more problems during the activity II than during the activity I, while three groups generated more problems during the activity I. Therefore, there was no clear relation between the number of problems generated, the type of activity, and more or less complex problem situations.

However, with the exception of one group (B) who did not generate an appropriate inquiry problem during the activity I, fewer inquiry problems were produced during the activity II. A possible explanation for this difference between the two types of activities was identified through the examination of breadth versus depth of questions posed by the students. For example, group E came up with 14 inquiry problems during the activity I and one third of which were related to water. Their inquiry problems about water were, "Why is water transparent? What happens if we pour water over peppermint candy? Why not sell water in cartons? Do seeds dissolve in water? Can seeds grow only with water?" Two of them were integrated with the seed, another material given in the worksheet. Overall there were fewer materials to look at during the activity I, and thus students could think about the materials deeply and connect between two different materials. In contrast, problems generated during the activity II were rarely about the same topic.

Table 3 Nature of student questions

\begin{tabular}{|c|c|c|c|c|c|c|c|c|c|c|c|c|c|}
\hline \multirow{2}{*}{$\begin{array}{l}\text { Group ID } \\
\text { Activity }\end{array}$} & \multicolumn{2}{|l|}{ A } & \multicolumn{2}{|l|}{$B$} & \multicolumn{2}{|l|}{ C } & \multicolumn{2}{|l|}{$E$} & \multicolumn{2}{|l|}{$F$} & \multicolumn{2}{|l|}{ G } & \multirow[t]{2}{*}{ Average } \\
\hline & I & $\|$ & I & $\|$ & I & $\|$ & 1 & $\|$ & I & $\|$ & I & $\|$ & \\
\hline No. of problems & 36 & 51 & 45 & 30 & 39 & 27 & 40 & 23 & 30 & 41 & 33 & 33 & 36 \\
\hline Inquiry problems & 9 & 6 & 0 & 4 & 21 & 5 & 14 & 2 & 5 & 3 & 13 & 8 & 8 \\
\hline Creative problems & 17 & 6 & 0 & 4 & 15 & 4 & 12 & 2 & 5 & 2 & 13 & 5 & 7 \\
\hline
\end{tabular}


When we coded the creativity of problems generated by the students, we also found that problems generated during the activity I were more creative than the ones generated during the activity II. On average, seven questions per each activity were coded as creative questions. However, all but group B produced more creative questions during the activity I. Thus, it seems that a less complex problem situation was more conducive to inquiry and creative problems. Students seemed to be less bounded by the given materials.

In the activity II, however, students demonstrated their relevant scientific knowledge more frequently than in the activity I. For example, as shown in the following excerpt, a student of group $\mathrm{E}$ stated his knowledge related to each of the photos in the worksheet:

What comes to mind is air pollution and the greenhouse effect. The greenhouse effect is when greenhouse gases won't let heat or ultraviolet rays go out of the earth but stay, resulting in global warming. (Pointing at a picture) You all would know about frictional force. Volcanoes and earthquakes. If there is an earthquake, there are volcanoes. First of all, earthquakes occur when two [plates] moving away, moving sideways, or colliding. Then, one (plate) rises and the other sinks .... (II-E2).

However, students' relevant knowledge did not necessarily help in creating inquiry problems, which were more often posed during the activity I (Table 2). Rather, students' relevant knowledge turned out to limit problem discovery. As in the following excerpts, students were discouraged from pursuing their questions further when group members answered questions with scientific terms and knowledge. When a problem was offered and group members give solutions to the problem with some knowledge, the problem was instantly off the table.

II-B4: How far can the sound of thunder go?

II-B2: It can go as far as sound waves can go.

II-G2: Why this ship doesn't sink even though it is loaded so much?

II-G4: Because of buoyancy.

On the other hand, emotional engagement along with emotional support by peers such as agreement with excitement seemed to be effective in finding problems and sophisticating inquiry problems. Group A's conversation during the activity II, along with their interviews, illustrate how member's response and strong agreement created a supportive environment that led to student engagement in problem finding.

II-A2: At what degree, does water freeze?

II-A1: Hey! Then, salt water contains salt. So the sea water doesn't freeze. How much salt should it contain in order not to freeze?

II-A3: Wow! That is GREAT!

II-A2: Awesome!

The previous class seems a bit different. I think it's good to be able to see what we don't know one by one ... I'm not tired of listening to my friends. It was good. Simply good. (Interview with A1). 
If you keep doing these kinds activities, you start with your own questions and go forward step by step. The activity is fun and I think it's good to keep learning science this way. The textbooks have experiments and we just finish them. But I think this activity is really good because you can find out what you are curious about. (Interview with F3).

\section{Productive conversation}

Utterances of evaluating problems could be an indication of the degree to which group members responded to problems offered, and helped students focus on scientifically meaningful questioning. This form of conversation that facilitates students' scientific problem finding is called productive conversation in this study following Engle and Conant (2002). Adapting the qualities of scientific inquiry problem (Table 1) presented to the students, the students in this study used five distinctive criteria in evaluating their questions. These include (a) testability or measurability, (b) answerability through Web search, (c) answers known to the students, (d) contradictions in problems, and (e) unfounded emotional or intuitive judgment (Table 4).

In both activities, the group with the most problem evaluation utterances was group $\mathrm{G}$ (Table 4). In both activities, group G evaluated most problems offered (79\% and 85\%), whereas the other groups had a small proportion of evaluation utterances (10 37\%). It is likely that the more evaluation utterances involve the more diverse criteria. However, a comparison of two distinct groups showed otherwise. The proportions of evaluation utterances were consistent across two activities in most groups, but groups $\mathrm{A}$ and $\mathrm{F}$ demonstrated notable differences. In the case of group A, the proportion of problem evaluation in the activity II was significantly reduced, compared to the activity I. In the case of group F, problem evaluation increased significantly in the activity II (Table 5). When the types of evaluation criteria used were examined, it was found that students tended to use more various criteria in the activity II than the activity I, regardless of the frequency of evaluation utterance. During the activity I, group A used two types of criteria, while group F used only one type (Table 5). On the other hand, group A used three types, and group F used four types in the activity II. Thus, in both group A and F, the students used more diverse criteria in the activity II. This indicates no significant pattern between evaluation frequency and the diversity of evaluation criterion. In other words, the diversity of evaluation criterion was irrelevant to the frequency of evaluation utterances.

A contrast between unproductive and productive conversation can be exemplified with the differences in group F's conversation patterns across two activities. The comparison points to the importance of problem evaluation utterance for productive problem finding. As shown in the following conversation, during group F's participation in the activity II, the question of minerals (by F4) and the question of electric conductivity of water (by F3) were proposed simultaneously. Then F3 answered F4's question, while F2 spun off F4's question. Without responding to F2's new question, F3 repeated his question. To these questions, F1 added his own question. This is a type I conversation where students rarely evaluate problems offered, and kept proposing different problems.

I-F4: Why are there minerals in water? Are there minerals in seeds? /I-F3: Why does water conduct electricity? 
Table 4 Evaluation utterances

\begin{tabular}{|c|c|c|c|c|c|c|c|c|c|c|c|c|c|}
\hline \multirow{2}{*}{$\begin{array}{l}\text { Group ID } \\
\text { Activity }\end{array}$} & \multicolumn{2}{|l|}{ A } & \multicolumn{2}{|l|}{ B } & \multicolumn{2}{|l|}{$\mathrm{C}$} & \multicolumn{2}{|l|}{$E$} & \multicolumn{2}{|l|}{$\mathrm{F}$} & \multicolumn{2}{|l|}{ G } & \multirow[t]{2}{*}{ Average } \\
\hline & I & $\|$ & I & $\|$ & I & $\|$ & I & $\|$ & I & ॥ & I & $\|$ & \\
\hline Evaluation utterance per question (\%) & 28 & 10 & 40 & 27 & 10 & 15 & 10 & 17 & 10 & 37 & 79 & 85 & 31 \\
\hline Criteria & & & \multicolumn{11}{|c|}{ Examples of Evaluation utterance } \\
\hline Testability or measurability & & & \multicolumn{11}{|c|}{$\begin{array}{l}\text { Hey! That's not what we can do. We have to experiment it } \\
\text { for ourselves. } \\
\text { I think it is okay because we can test it. } \\
\text { Can't you measure it? }\end{array}$} \\
\hline Answerability through Web search & & & \multicolumn{11}{|c|}{$\begin{array}{l}\text { When you search the internet everything can be found. It's } \\
\text { not something we can test. }\end{array}$} \\
\hline Answers known & & & \multicolumn{11}{|c|}{$\begin{array}{l}\text { That is so obvious. Why are we doing it? / That's just right } \\
\text { (no need for exploration). }\end{array}$} \\
\hline Contradictions in problems & & & \multicolumn{11}{|c|}{ "Why can't soil photosynthesize?" Because it isn't a plant! } \\
\hline Unfounded judgment & & & \multicolumn{11}{|c|}{$\begin{array}{l}\text { Well, that's not good. / Isn't that a bit weird? / I am curious } \\
\text { too. }\end{array}$} \\
\hline
\end{tabular}

I-F3: Because there are minerals in the soil.

I-F2: What do the minerals in water do?

I-F3: Why does water conduct electricity?

I-F1: Why is water composed of droplets?

During the activity II, however, group F demonstrated a different type of conversation, demonstrating the power of evaluation utterance made as a response to a problem proposed. In response to F3's problem, F4 evaluated that it is testable, and the rest of the utterances built on one another until a valid test design was agreed upon. Here, a student's evaluation of testability seemed to lead to elaborations of the problem (the second problem offered by F3) and a discussion on how to test the problem. Thus, it seemed that the problem evaluation process helped students keen on generating scientific inquiry problems.

II-F3: Why is this big? (Point to racing car wheel).

II-F4: We can test it with a big and a small wheel like this (size gestures).

II-F3: Does this run more distance than the other one when the wheel turns one circle? Of course this one. That is why (it is big). Ah! I can't talk well. Because (big wheels) go farther than small wheels.

II-F4: You can compare one turn (of each). For example, this one goes about $1 \mathrm{~cm}$ and this one goes about $5 \mathrm{~cm}$.

Table 5 Evaluation utterance patterns exemplified in groups A and $F$

\begin{tabular}{|c|c|c|}
\hline Activity & Group A $(28 \% \rightarrow 10 \%)$ & Group F (10\% $\rightarrow$ 37\%) \\
\hline Single material & $\begin{array}{l}\text { "Do seeds sprout in water?" That is obvious. } \\
{[\text { ANS }]^{\mathrm{a}}} \\
\text { Oh, that sounds great! [UNF] }\end{array}$ & $\begin{array}{l}\text { It a really, really good idea. [UNF] } \\
\text { That is embarrassing! [UNF] }\end{array}$ \\
\hline $\begin{array}{l}\text { Composite } \\
\text { material }\end{array}$ & $\begin{array}{l}\text { We can't test it. That is not an inquiry. [TET] } \\
\text { This is too obvious. [ANS] } \\
\text { Does that make sense? It is like asking, "Why } \\
\text { do cats and dogs live on ground?" [CON] }\end{array}$ & $\begin{array}{l}\text { You can experiment with this. [TET] } \\
\text { But you can answer it using the internet. } \\
\text { [INT] } \\
\text { It is so, so obvious! [ANS] } \\
\text { That is good! [UNF] }\end{array}$ \\
\hline
\end{tabular}

${ }^{a}$ Coding: [TET] testability or measurability, [INT] answerability through Web search, [ANS] answers known, [CON] contradictions in questions, and [UNF] unfounded emotional or intuitive judgment 
II-F3: Circumferences are different. Circumferences!

II-F4: Then this one (big wheel) is better.

II-F2: But it depends on the motor. This has the smallest (wheels) but it has V8 motor.

II-F4: Then, we can use the same motor but different sizes of wheels.

II-F2: Right.

\section{Discussion}

In this study, we examined the nature of elementary students' problem finding in science learning through small group conversation patterns and conditions for productive problem-finding participation. The findings showed that typical elementary students in this study were able to actively engage in problem-finding activities. They kept mostly on task, and enjoyed the activity. We identified three different problem-finding conversation patterns and conditions for productive questioning and conversation about scientific problems, which provided insights into ways to facilitate students' problem finding in science learning.

The three types of problem-finding conversation seem to be natural when students brainstorm problems (type I or II), and when they choose a problem to focus on (types II). Type I should be encouraged in the beginning of problem finding activity, when students' initial intuitive and curious questions arise. What teachers can do is to help students record their questions as professionals usually do, so that students can value their own intuition and curiosity. Type II showed a strategy for reshaping problems for the purpose of refining them as testable problems. During problem-finding activities, teachers can encourage students to modify their initial questions by changing a small part to make it more scientific and feasible. Type III should be encouraged after initial brainstorming for the purpose of refinement of problems. Otherwise, students might be discouraged from proposing problems because of criticism, or because of direct answers from more knowledgeable students. Also important is to ensure students' openness to evaluating problems. Once the problems are on the table, they should be considered as group assets, rather than belonging to a specific individual. In doing so, criticism and evaluation would be taken as group efforts to improve the problems, rather than personal attacks.

While the literature on problem findings suggest that ill-defined problem situations can be more productive for creative problem finding, the findings of this study further suggest that not only ill-defined situations, but also less complex materials would provide more room for student productivity and creativity in problem discovery. The findings also showed that students' knowledge could be a limiting factor for meaningful problem finding. Students in this study produced more inquiry problems in an activity with less complex materials than more complex materials. Also, the problems generated in the activity with less complex materials were more creative. This is consistent with what Ryu and Park (2006) found with high school students. Taken together, simple materials function better for creative problem-finding activities, and teachers should help students use their background knowledge in a productive way, instead of closing further discussion on the problems offered. Sophistication of problems with scientific knowledge is an important process of problem finding in real science, and thus 
guidance is needed on how knowledge can be used to refine problems. Teacher guidance in using scientific background knowledge as a way to open doors to refining initial problems, rather than for closing discussion, should be provided.

The findings also demonstrated that evaluation utterance is critical for students' productive participation in problem finding. Furthermore, the quality of evaluation utterance is more important than its quantity. As expected, intuitive unfounded evaluation utterance was not effective. Thus, teacher guidance on what kind of evaluation utterances are useful for problem-finding activities, and when to use them, would make a difference.

The follow-up interview revealed that students enjoyed the activities, and that they contrasted it with textbook science inquiry. Just as a study of textbook analysis in South Korea demonstrated, current science classes in South Korea do not promote students' problemfinding activity (Kang \& Lee, 2013). Given the importance of creative skills in the twentyfirst century science education, students should have more opportunities to find their own scientific problems in learning science. This study provided a picture of what can be expected from elementary students when they are engaged in problem-finding activities and suggested strategies for teachers to use to make the activity productive.

Because this study examined only six groups from two schools, there might be other different patterns of student participation in problem finding. Further research on the process and materials helpful for student problem finding will help to understand the nature of students' problem finding in science learning, and ways to make it rich and productive. Also, studies about students from different educational contexts might provide pictures of student participation different from the ones reported in this study. Unlike students in South Korea, will students who are used to problem-finding activities demonstrate different patterns of participation? A long-term study in South Korea, or a study of students from a different educational context will help answer these questions.

Acknowledgements

Not applicable.

\section{Authors' contributions}

$\mathrm{KO}$ and NK co-designed the study, NK advised KO's data collection and initial analysis of the data for this master's thesis published in February 2018. KO and NK collaboratively re-analyzed the data further for this manuscript. The analysis method and the results presented in this paper are mostly different from the analysis published in the thesis. NK wrote this paper in consultation with KO. All authors read and approved the final manuscript.

Funding

Not applicable.

Availability of data and materials

The data is collected in South Korea and will be available upon reasonable request.

Authors' Information

Kicheol Oh is an in-service elementary teacher as well as a doctoral student at Korea National University of Education (KNUE), South Korea. He has been teaching at the elementary school level for more than ten years. His research interests include promoting creativity in science learners and understanding diverse learners' science learning.

Nam-Hwa Kang is a professor at Korea National University of Education (KNUE), South Korea. Before she joined KNUE in 2012, she was an assistant professor at University of Nevada, Las Vegas, and an assistant and associate professor at Oregon State University in the United States. Her research centers on science teaching practices in relation to epistemic practices in science. She published papers that address connections between science teacher beliefs about science learning, science inquiry, modelling in science, and scientific argumentation and teaching practices. Her recent projects include defining and supporting science teaching competency development and assessing the impact of integrated STEAM (Science-Technology-Engineering-Arts-Mathematics) reform. Her recent project also includes understanding scientific literacy development based on data mining. Currently, she is the editor-in-chief of a journal, Innovation \& Education published by BMC (part of Springer Nature) and an associate editor of the journal Asia-Pacific Science Education. 


\section{Competing interests}

The authors declare that they have no competing interests.

\section{Author details}

${ }^{1}$ Department of Elementary Education, Korea National University of Education, Cheongju, Republic of Korea.

${ }^{2}$ Department of Physics Education, Korea National University of Education, Cheongju, Republic of Korea.

Received: 24 September 2019 Accepted: 13 November 2019

Published online: 13 December 2019

\section{References}

Bruner, J. (1996). The culture of education. Cambridge: Harvard University Press.

Duschl, R. A., Schweingruber, H. A., \& Shouse, A. W. (Eds.). (2007). Taking science to school: Learning and teaching science in grades $K^{-8}$. Washington, D. C: National Academy Press.

Engle, R. A., \& Conant, F. R. (2002). Guiding principles for fostering productive disciplinary engagement: Explaining an emergent argument in a community of learners classroom. Cognition and Instruction, 20(4), 399-483. https://doi.org/10. 1207/S1532690XCI2004_1.

Getzels, J. W. (1979). Problem finding: A theoretical note. Cognitive Science, 3, 167-172.

Hoover, S. M., \& Feldhusen, J. F. (1994). Scientific problem solving and problem finding: A theoretical model. In M. A. Runco (Ed.), Problem finding, problem solving and creativity. Norwood: Ablex.

Kang, N.-H., \& Lee, E. (2013). 2015 개정 과학교육과정에 따른 고등학교 물리 교과서 탐구활동 분석 [An analysis of inquiry activities in high school physics textbooks for the 2009 revised science curriculum]. Journal of Korean Association for Science Education, 33(1), 132-143.

Kaufman, J. C., Plucker, J. A., \& Baer, J. (2008). Essentials of creativity assessment. New York: Wiley.

Kim, M., \& Lee, S. (2013). 초등 과학영재와 일반 학생의 과학탐구문제 발견 능력에 대한 비교 [A comparison of science inquiry problem finding ability of gifted elementary students of science and general elementary students]. Journal of the Korean Elementary Science Education, 32(4), 464-472.

Kim, Y., Seo, H.-A., \& Park, J. (2013). 잘 알려진 창의적 과학자들의 과학적 문제 발견 패턴 분석 [An analysis on problemfinding patterns of well-known creative scientists]. Journal of Korea Association of Science Education, 33(7), 1285-1299.

Korea Ministry of Education. (2015). 2015 개정 과학교육과정[2015 revised science curriculum]. Sejong: Ministry of Education 2015-74 [issue 9.

Kozbelt, A., Beghetto, R. A., \& Runco, M. A. (2010). Theories of creativity. In J. C. Kaufman \& R. J. Sternberg (Eds.), The Cambridge handbook of creativity (pp. 20-47). New York: Cambridge University Press.

Kuhn, D., Black, J., Keselman, A., \& Kaplan, D. (2000). The development of cognitive skills to support inquiry learning. Cognition and Instruction, 18(4), 495-523. https://doi.org/10.1207/S1532690XCl1804_3.

NGSS Lead States. (2013). Next general science standards: For States, by States. Washington, D.C.: The National Academies Press.

Lee, S., Son, J., Kim, J., Park, J., Seo, H., Shim, K., et al. (2013). 고등학교 과학수업 사례 분석을 통한 학교 과학 탐구의 특징 [Characteristics of school science inquiry based on the case analyses of high school science classes]. Journal of the Korean Association for Science Education, 33(2), 284-309.

Lee, S.-K., Choi, C. I., Lee, G., Shin, M.-K., \& Song, H. (2013). 초등 과학 수업 담화에서 나타나는 과학적 추론 탐색 [Exploring scientific reasoning in elementary science classroom discourse]. Journal of the Korean Association for Science Education, 33(1), 181-192.

Lemke, J. L. (1990). Talking science: Language, learning, and values. Norwood: Ablex.

Mansfield, R. S., \& Busse, T. V. (1981). The psychology of creativity and discovery. Chicago: Nelson-Hall.

Mayer, R. (2006). The role of domain knowledge in creative problem solving. In J. C. Kaufman \& J. Baer (Eds.), Creativity and reason in cognitive development (pp. 145-158). Cambridge: Cambridge University Press.

Merriam-Webster's Online Dictionary (2019). Problem. Retrieved from https://www.merriam-webster.com/dictionary/problem

National Research Council. (2012a). A framework for K-12 science education: Practices, crosscutting concepts, and core ideas. Washington, DC: The National Academies Press. https://doi.org/10.17226/13165.

National Research Council. (2012b). In J. W. Pellegrino \& M. L. Hilton (Eds.), Education for life and work: developing transferable knowledge and skills in the 21st century. Washington D. C.: The National Academies Press.

Psychology Dictionary (2019). Utterance. Retrieved from https://psychologydictionary.org/utterance/

Runco, M. A., \& Chand, I. (1994). Problem finding, evaluative thinking, and creativity. In M. A. Runco (Ed.), Problem finding, problem solving, and creativity (pp. 40-76). Norwood: Ablex.

Ryu, S.-K., \& Park, J.-S. (2006). 낮게 구조화된 과학적 문제 상황에서 고등학생들의 문제발견 활동 분석 [An analysis of high school students' activity on problem-finding in ill-structured scientific problem situation]. Journal of the Korean Association for Science Education, 26(6), 765-774.

Ryu, S.-K., \& Park, J.-S. (2008). Analysis of the scientific inquiry problem generated by the scientifically-gifted in ill- and wellstructured inquiry situation. Journal of the Korean Association for Science Education, 28(8), 860-869.

Smith, S. M. (1995). Fixation, incubation, and insight in memory and creative thinking. In S. M. Smith, T. B. Ward, \& R. A. Finke (Eds.), The creative cognition approach (pp. 135-156). Cambridge: MIT Press.

Treffinger, D. (1995). Creative problem solving: Overview and educational implications. Educational Psychology Review, 7(3), 301-312 Retrieved from http://www.jstor.org/stable/23359352.

Treffinger, D. J., Isaksen, S. G., \& Dorval, K. B. (2000). Creative problem solving. Waco: Prufrock Press.

Wakefield, J. F. (1994). Problem finding and empathy in art. In M. A. Runco (Ed.), Problem finding, problem solving, and creativity (pp. 99-115). Norwood: Ablex.

Weisberg, R. W. (2006). Creativity: Understanding innovation in problem solving, science, invention, and the arts. Hoboken: Wiley.

\section{Publisher's Note}

Springer Nature remains neutral with regard to jurisdictional claims in published maps and institutional affiliations. 